\title{
THE NEW NURSING QUALIFICATIONS FRAMEWORK
}

\author{
M Bezuidenhout, Tshwane University of Technology; \\ S Human, UNISA; \\ M Lekhuleni, University of Limpopo-Turfloop
}

\begin{abstract}
The impetus for the restructuring of higher education in South Africa was political rather than educational in nature and gained momentum since the democratization of the country in 1994. The main purpose was the transformation of education and to increase accessibility to higher education opportunities for those who were previously disadvantaged and marginalised in terms of career progression. The emphasis on recognition of prior learning (RPL) to provide access to career progression was a further strategy to support the underlying principle of a national qualification framework which allowed for articulation between qualifications and provided individuals with upward mobility. The Council for Higher Education (CHE), in its ten-year review of the restructuring process, concluded that the transformation of higher education was "highly complex, consisting of a set of unfolding discourses of policy formulation, adoption and implementation that are replete with paradoxes and tensions, contestations and social dilemmas." (CHE, 2004: 234). Based on this conclusion, it can safely be assumed that the changes in the higher education domain seen over the past years will continue in the future. The higher education scene is flexible and dynamic and adhering to policies and structures and complying with norms and standards poses continuous challenges for providers of education, including the nursing profession.

The purpose of this chapter was to give a brief overview of the progression of nursing education over two decades, illustrating how nursing programmes evolved to meet the needs of the community, as well as complying with the quality standards and higher education criteria for acceptability and registration.
\end{abstract}

Keywords: NQF; CHE; SANC

\section{Introduction}

Since the early 1990s, the focus of healthcare in South Africa changed from hospital-centred care to a primary healthcare approach. Health services were decentralised to district and local levels in an attempt to deliver more affordable, accessible and acceptable basic health care to as large a sector of the population as possible. The nursing fraternity, which forms the largest component of healthworkers was, and still is, essential to nurse-based primary healthcare delivery in South Africa. The training of nurses, which was mainly hospital-based consequently became community-based, and the knowledge and competencies required from nurses were extended to address the shortage of other members of the health team at primary healthcare level and enabled nurses comprehensively to address the basic health needs of the communities which they serve.

The impetus for the restructuring of higher education in South Africa was political rather than educational in nature and gained momentum since the democratization of the country in 1994. The main purpose was the transformation of education and to increase accessibility to higher education opportunities for those who were previously disadvantaged and marginalised in terms of career 
progression. The emphasis on recognition of prior learning (RPL) to provide access to career progression was a further strategy to support the underlying principle of a national qualification framework which allowed for articulation between qualifications and provided individuals with upward mobility. The Council for Higher Education (CHE), in its ten-year review of the restructuring process, concluded that the transformation of higher education was "highly complex, consisting of a set of unfolding discourses of policy formulation, adoption and implementation that are replete with paradoxes and tensions, contestations and social dilemmas." (CHE, 2004: 234). Based on this conclusion, it can safely be assumed that the changes in the higher education domain seen over the past years will continue in the future. The higher education scene is flexible and dynamic and adhering to policies and structures and complying with norms and standards poses continuous challenges for providers of education, including the nursing profession.

In an attempt to explain the current nursing qualifications framework, this chapter provides a brief overview of the higher education system in South Africa by contextualizing nursing education and the changes in nursing education since 1990.

\section{The role of the South African Nursing Council in nursing education}

In terms of relevant legislation, including the Constitution, Act No. 108 of 1996, the National Health Act, 61 of 2003 and the Nursing Act 33 of 2005, the Government of South Africa has the responsibility to deliver healthcare to the entire population. As a statutory body, the South African Nursing Council (SANC) is legally tasked with promoting and maintaining standards in nursing education in the country and also with ensuring appropriate, safe and ethically sound professional nursing practice of a high quality. The SANC therefore has the responsibility to regulate the training of nurses, accredit training facilities, monitor the process of nursing education in different institutions and enable nurse practitioners to practise through a process of licensing and registration.

The training of nurses in South Africa from 1990 to 2004 was regulated by the Nursing Act 50 of 1978, as amended. This Act made provision for the training of student nurses and pupil nurses respectively who, upon qualifying, were licensed by the South African Nursing Council to practise as registered nurses, midwives, enrolled nurses or nursing auxiliaries. Registered nurses functioned independently, while the scope of practice for enrolled nurses and nursing auxiliaries regulated their practice under direct and/or indirect supervision by registered nurses.

A new Nursing Act, 33 of 2005 was partly promulgated in 2005. Section 31 of this Act regulated nurse practitioners and enabled them to practise as professional nurses, midwives, staff nurses, auxiliary nurses or auxiliary midwives. The insufficient numbers of nurse practitioners in the country and the comprehensive knowledge and extended competencies required from nurses so that they could deliver a high-quality service to an increasing population in a resource-scarce environment, demanded an in-depth review of nursing education. Road shows were conducted by SANC in 2004 to obtain input from stakeholders in order to design appropriate new spheres of practice for professional nurse and staff nurse categories. In terms of these scopes of practice, each category of nurse registered with the South African Nursing Council was entitled to function independently within their specific scope of practice.

\section{Nursing programmes prior to 1994}

Nursing education in South Africa commenced in 1899, with South Africa being the first country in the world to regulate and register its nurses. Several programmes evolved since that time as the 
needs and pressures for appropriate and safe healthcare increased. The first degree programme in nursing was instituted at the University of Pretoria in 1955. By 1994, the nursing programmes were divided into pre- and post-registration programmes, as indicated by Mekwa (2000: 271).

\section{Pre-registration programmes}

- A certificate programme leading to a qualification as an enrolled auxiliary nurse. This was mainly implemented through in-service training, the duration of which varied depending on the institution.

- A two-year certificate programme leading to a qualification as an enrolled nurse in accordance with SANC Regulation R1664, as amended and R2175.

- A two-year Diploma in General Nursing (referred to as the Bridging Programme) leading to registration as a general or psychiatric nurse in accordance with the SANC Regulation R683, as amended.

- An integrated four-year diploma or degree qualification which included General, Psychiatric and Community Health Nursing and Midwifery in accordance with SANC Regulation No R425, as amended. This programme will be discussed briefly below:

In line with the establishment of a nurse-based primary healthcare approach in South Africa, the abovementioned integrated four-year nursing programme leading to registration as General, Psychiatric and Community Health Nurse and Midwife was implemented in 1984. The central motivation for this programme was to prepare a generalist nurse-midwife who could function in primary healthcare as well as hospital settings. The programme also aimed at making psychiatric/mental health nursing part of entry level registered nurse training in order to prepare for the integration of psychiatric care in the general health system. Lastly, it included community health in order to prepare the nurse to be able to practise outside hospitals. This programme was also thought to be more cost-effective, since the generalist nurse was prepared in four years at a student nurse-level cost. In the past, general nurses trained for three years and could then obtain the three additional qualifications (midwifery, community health nursing and psychiatric nursing) taking one year for each, making the total time to prepare a generalist nurse-midwife six years. What is more, the three additional qualifications had to provide for the trainee at a registered nurse level of remuneration and $s /$ he often had great difficulty accessing such programmes in rural areas. There was initially some debate about whether the separate registrations for general-, community health- and psychiatric nursing should be maintained, or one single registration implemented. In the end, the separate registrations were kept, which led to neophyte nurses entering the profession with an epaulette and three bars, a significant change for the profession.

The specific Regulation R425 included a requirement that nursing colleges offering this programme, under the management of a Nursing College Principal, had to be affiliated with a university as a measure of quality control. Memoranda of understanding in this regard were signed between the Department of Health, as the controlling body of public nursing college, and the respective Universities. This initiative of affiliation between nursing colleges and universities moved nursing education of registered nurses directly into the sector for formal post-secondary education and was acknowledged as such (Kotzé 1995: 23).

\section{Post-registration programmes}

- Post-basic certificates (known as short courses);

- Supplementary basic diplomas; 
- Post-basic/post-registration diplomas which lead to a variety of single diploma qualifications in fields such as Nursing Education, Nursing Administration, Community Health Nursing, Paediatrics, Orthopaedics, Theatre training, Intensive Care and others;

- Post-basic/post-registration Bachelor degree programmes leading to specialisation in Nursing Education, Nursing Administration and Community Health Nursing, usually offered as combined qualifications in terms of these various disciplines;

- Honours, Master's and Doctoral programmes which included various levels of research.

\section{The National Qualifications Framework (NQF)}

In line with international trends to ensure quality, formulate comparable standards and provide a vehicle for focused, needs-driven and coherent training in a country, a national, eight-level qualifications framework was developed in 2000 (see table 2.1). This meant that all qualifications offered in the country had to fit into one of these levels and had to comply with the level requirements. Its implementation was overseen by the South African Qualifications Authority (SAQA).

The initial unit standard approach which allowed a student to use a basket approach and to choose from various unit standards to "build" whole qualifications, in many instances resulted in qualifications that were meaningless in terms of the focus and purpose of a qualification. The intention of whole qualifications was clearly not achieved by the completion of loose standing parts. The lack of alignment between the purpose of the qualification, the outcomes and the need for integrated assessment criteria, are some of the main reasons for the later rejection of the unitstandard model of the qualification structure.

The generic critical cross-field outcomes incorporated in the design of the NQF served as an additional mechanism to establish coherence in qualifications, regardless of the specific area or content of learning. These critical cross-field outcomes are deemed critical for the development of the capacity for life-long learning and are intended to direct the thinking of policy-makers, curriculum designers, facilitators of learning, as well as the learners themselves, to ensure selfdevelopment, cultural and aesthetic awareness, and the ability to explore entrepreneurial opportunities.

On the other hand, whole qualifications that are not structured in terms of units and parts may result in a failure to adhere to the principles embedded in the NQF in terms of access, progression, portability and articulation. The importance of transparency, measurable standards and quality in terms of recognition of prior learning (RPL) policies and processes to recognize completed learning and to avoid duplication can, therefore, not be over-emphasised.

An important element within the NQF is that of applied competencies. An applied competency is defined as the ability to put into practice, in the relevant context, the learning outcomes acquired in obtaining a qualification. Foundational competence (understanding of what is being done and why), practical competence (the demonstrated ability to perform a specific task) and reflexive competence (the demonstrated ability to integrate and connect performance, with the ability to adapt to change and unforeseen circumstances), are essential elements in all qualifications. However, some critics feel that the stress on competence in outcomes-based education puts so much focus on action, that exposing students to the values and underlying ethical principles of a discipline is often neglected. This criticism has particular relevance to the development of curricula for nurses in terms of the importance of the ethical framework within which nursing should be practised. In reviewing the implementation of the eight-level NQF, it was found that academics, in an attempt to adhere to the 
formats prescribed by SAQA, focused on the composition of programmes in terms of the different kinds of modules (fundamental, core and elective), In this process, little consideration was given to fundamental curriculum reforms (Review of Higher Education in South Africa2007: 166). Curricula developers and providers of educational programmes have to ensure that applied knowledge and competencies should be non-hierarchical, inter- and trans-disciplinary, fast- changing, contextualized and socially responsive to real-world contexts.

Table 2.1: The NQF levels of South Africa

\begin{tabular}{|c|c|c|}
\hline Levels & Eight level NQF (2000) & Ten level NQF (2010) \\
\hline \multirow{2}{*}{5} & National certificate -120 credits & \multirow{2}{*}{ Higher certificate - 120 credits } \\
\hline & National diploma - 240 credits & \\
\hline \multirow{3}{*}{6} & National certificate -120 credits & Advanced certificate -120 credits \\
\hline & National diploma - 240 credits & Diploma - 360 credits \\
\hline & Bachelors - 360 credits & \\
\hline \multirow{5}{*}{7} & National certificate -120 credits & \\
\hline & National diploma - 240 credits & \\
\hline & Bachelor's (professional) - 480 credits & \\
\hline & B. Tech - 480 credits & \\
\hline & Bachelors/Honours - 120 credits & \\
\hline \multirow{7}{*}{8} & National certificate -120 credits & $\begin{array}{c}\text { Bachelor's degree (professional) }-480 \\
\text { credits }\end{array}$ \\
\hline & National diploma - 240 credits & $\begin{array}{c}\text { Bachelor's/Honours' degree }-120 \\
\text { credits }\end{array}$ \\
\hline & Master's - 180 credits & Postgraduate diploma - 120 credits \\
\hline & M. Tech -180 credits & \\
\hline & Doctoral -360 credits & \\
\hline & D. Tech -360 credits & \\
\hline & Post-doc & \\
\hline 9 & Not applicable & Master's degree - 180 credits \\
\hline 10 & Not applicable & Doctoral degree -360 credits \\
\hline
\end{tabular}

(Source: SAQA. www.saqa.org.za Accessed 2011-08-29)

Another barrier to the effective implementation of the NQF was the demands set by the various committees that were instituted in terms of the SAQA Act, such as the National Standards Bodies (NSB) and the Standard Generating Bodies (SGB). These structures comprised various stakeholders in addition to academics, educators and subject specialists and included representatives from industry, non-governmental organizations and other non-academics. In many instances, however, these representatives were accused of "not having an understanding of the academic environment", having pursued their own agendas and interests (Review of Higher Education in South Africa 2007: 168).

The role and influence of professional councils (including the SANC) in the development of qualifications in line with the SAQA Act and the NQF proved to be unclear and further contributed to the challenges of designing and registering qualifications in terms of the NQF. 


\section{- The South African Qualifications Authority (SAQA)}

The establishment of SAQA brought about the creation of a number of bodies involved with the development and standardisation of training across all sectors. The following brief explanation of the different bodies and their functions is based on a document by SAQA entitled The National Qualifications Framework and Standards Setting published in 2000.

The South African qualifications authority (SAQA), also called "the Authority", was established through the SAQA Act No 58 of 1995 to oversee the development and implementation of the National Qualifications Framework (NQF). The NQF is a means for transforming education and training in South Africa and has been designed to:

- Create a single, integrated, national education and training framework for the whole nation

- Make it easier for learners to enter the education and training system and to move and progress within it

- Improve the quality of education and training in South Africa

- Enable learners to develop to their full potential, thereby supporting the social and economic development of the country as a whole.

SAQA's vision was to develop an educational system that reflects the objectives of the NQF. The mission was to ensure the development and implementation of the NQF.

In terms of section 5(1) of the South African Qualifications Authority Act, No 58 (1995), SAQA had to oversee the development of the NQF, formulate and publish policies and criteria for registration and accreditation of bodies in the field and oversee implementation of the NQF.

\section{- $\quad$ National Standards Bodies (NSBS)}

NSBs were registered bodies under the SAQA Act that were responsible for establishing education and training qualifications and/or standards

Specific functions of NSBs were to

- Define and recommend to SAQA the boundaries in a specific field;

- Define and recommend a framework of sub-fields which were to be used as a guide for SGBs;

- Recognise and/or establish SGBs within the framework of a sub-field, and ensure that the work of the SGBs meets SAQA requirements;

- Recommend the registration of qualifications and standards;

- Oversee the updating and review of qualifications and standards;

- $\quad$ Liaise with ETQAs through SAQA;

- Define requirements and mechanisms for the moderation of qualifications and standards.

\section{- $\quad$ Standard Generating Bodies (SGBs)}

SGBs were registered bodies responsible for the generation of qualifications and/or standards. The recognition or establishment of the SGB was determined within the framework of the SAQA.

- Composition of SGBS

The composition of subject- or sub-field- specific SGBs included key education and training stakeholders in the sub-field, representatives from interest groups and specialists and usually comprised not more than 25 persons.

- Functions of SGBs were to

- Generate qualifications and standards;

- Update and review standards; 
- Recommend qualifications and standards to NSBs;

- Recommend criteria for the registration of assessors and moderators or moderating bodies;

- Perform such other functions as may from time to time be delegated by its NSB.

\section{- $\quad$ The Nursing SGB}

Twenty eight members of the nursing SGB were inaugurated in August 2001. Their first task was to do a scoping exercise and situational analysis of the current nursing education system in South Africa and internationally. Thereafter an occupational map was developed, considering the present qualifications and pegging them on the eight-level NQF as a basis from which to progress.

Much debate went into the format of qualifications to be developed and whether they should be in the form of whole qualifications or qualifications based on unit standards. The latter were accepted and unit standards were developed to form the building blocks of the different nursing qualifications. The reasons for the unit standard option included the underlying principle of allowing easy entry access, articulation and mobility and the potential to credit students for completed units with the potential to award exit qualifications at various exit levels.

Work groups were established and unit standards were developed during 2001 and 2002. In December 2002 proposed units were ready for narrow consultation with stakeholders, after which 60 unit standards comprising the different qualifications were submitted to SANC for consideration. These were approved a year later and submitted to SAQA in December 2003.

Throughout the process of developing the qualifications in terms of the eight-level NQF, a debate on revising and restructuring the NQF occurred in the Ministry of Education (South Africa 2004). This caused much confusion within constituted SGBs who, while working on qualifications in terms of the existing eight-level NQF, were requested also to comment on a draft restructured NQF, which later culminated in the current ten-level NQF.

During 2004, editing of the unit standards and qualifications for registered nurses was completed by SAQA, and in 2005 the certificates for the Auxiliary (Level 3) and Enrolled (Level 4) levels were aligned with the eight-level NQF. In 2006, a task team comprising members of SANC and SAQA was established with the aim of aligning the proposed new qualifications to relevant Scopes of Practice in terms of the new Nursing Act, No 33 of 2005.

In June 2007, the following qualifications were completed in accordance with the terms of reference of the Nursing SGB and the task team; namely, a National Diploma, Bachelor's in Nursing, Master's Certificates, Master's Degree and PhD in Nursing.

Soon thereafter a meeting took place between the SANC, SAQA, the Department of Health (DoH) and the SGB to discuss the implications of implementing the new set of nursing qualifications. Subsequently, a second narrow consultation process took place with all stakeholders in August 2007. This was followed by a follow-up meeting in November 2007 between SANC, SAQA, DoH and the $S G B$ to reach final agreement on the newly developed qualifications. At this meeting concern was expressed that the newly developed qualifications were not in line with the now proposed ten-level NQF as suggested by the HEQF in 2007. The nursing qualifications in terms of the eight-level NQF were nonetheless registered by SAQA on 28 November 2007.

\section{- Education and Training Quality Assurance Bodies (ETQAS)}

ETQAs were established by SAQA in specific sectors. In terms of the SAQA Act, SAQA had the responsibility to accredit organisations or groups of organisations to act as ETQAs. Members of the ETQA were drawn from appointed representatives of organizations or groups of people appointed in 
terms of the ETQA regulations. The South African Nursing Council (SANC) was deemed to be the designated ETQA for the nursing profession.

Functions of the ETQA include:

- Promoting quality amongst providers of education programmes or qualifications;

- Accrediting providers for specific qualifications and standards registered on the NQF;

- Evaluating assessment and facilitation of moderation amongst providers;

- Co-operating with relevant bodies appointed to moderate across ETQAs;

- Registering assessors for specified registered qualifications and standards in terms of the criteria established for this purpose;

- Monitoring the quality of service and training provision;

- Taking responsibility for the certification of learners;

- Recommending new qualifications and standards to NSBs for consideration, or modifying existing qualifications and/or standards.

\section{Repealing of the SAQA ACT and restructuring of the NQF}

In 2007, the NQF was adapted to a ten-level framework as promulgated by the NQF Act, No 67of 2008. The underlying principles and philosophy of the NQF did not change. The main reason for the adaptation lay in the realm of equivalence and portability of qualifications and the fact that the eight-level NQF did not easily permit sufficient differentiation between qualifications, particularly at the higher levels (see table 1).

The South African Qualifications Authority Act, No 58 of 1995 was repealed in its entirety by the Government Gazette No. 31909 of 17 February of 2009, section 37. SAQA, as a juristic body, however, continues with changed functions and responsibilities in terms of section 13 of the National Qualifications Act, 2008.

The role of SAQA within the NQF Act, 2008 changed to that of advancing the objectives of the NQF. This was done in terms of SAQA developing level descriptors for each of the ten levels in the NQF in consultation with Quality Councils (QCs), registering and publishing qualifications; collaborating with international counterparts, conducting research and maintaining a national learners' record.

In respect of SAQA's role in relation to professional bodies, SAQA has the responsibility to develop and implement policy and criteria for recognising a professional body and to register a professional designation after consultation with statutory and non-statutory bodies of expert practitioners, as well as registering its professional designation if the relevant criteria have been met. (www.saqa.org.za Accessed 2011-08-29).

ETQAs, as stipulated under the SAQA, were replaced by sector-based Quality Councils (QCS). These were responsible for the development and quality assurance of qualifications in the sectors of Basic Education (Umalusi); Higher Education and Training and Further Education (Council for Higher Education; $\mathrm{CHE}$ ) and Trades and Occupations (QCTO) respectively.

\section{Health Workforce studies}

The Pick Report recommended that the staffing ratios be revised such that the ratio of bed-toprofessional nurses exceeded the bed-to-enrolled nurse ratio (Pick, Nevhutalu, Cornwall \& Masuku 2001: 64) and that the scopes of practice of all categories of nurses should be aligned with the changes in healthcare systems such as the disease burden. The Pick Report also recommended the restructuring of human resources for health after identifying gaps during the study. The Nursing 
Strategy for Human Resources, in line with the Pick Report, aims at training a professional nurse who can address gaps in transformation and also introduce improvements in the practice of nursing (Department of Health 2008: 14). In line with the Nursing Act No 33 of 2005, the three categories of nurses proposed in the revised scopes of practice are Professional Nurse, Professional Midwife, Staff Nurse and Auxiliary Nurse. The nursing colleges should be revitalized in terms of the capacity of staff to provide training in the new qualification. There should be accreditation of Nursing Education Institutions to offer the revised and new nursing qualifications in order to strengthen the capacity of NEls to offer the new qualification. The existing outputs of the NEls do not match the health and service demands for nurses and midwives. The nursing strategy also addresses the shortage of nurses and midwives across all the healthcare services and advocates that strategies such as regulation implementation, nursing education, growth of nursing colleges, growth of nursing education in HEls and improved professionalism and quality of care should be applied (Department of Health 2011: 29). The four-year comprehensive diploma course that is offered at nursing colleges and one offered as a degree at universities, have been consolidated into a Bachelor of Nursing degree. The success of the implementation of the new qualification is dependent on the availability of the sufficient qualified nurse educators who hold a Master's degree or doctorate. The SANC has prepared new standards of nursing practice that incorporate procedures for accreditation and for regular monitoring of nurses in their places of work to ensure compliance with the standards (www.sanc.co.za).

\section{The new Nursing Qualifications Framework}

Globally, the nursing profession forms the backbone of healthcare provision. The quality, knowledge and skills of individual practitioners determine the strengths and weaknesses of any profession. Nursing education started off in hospitals as a form of "apprenticeship training" and the content was based on health needs determined by practice requirements. Quality control and standardisation were maintained in the form of national "board examinations" and registration of practitioners by professional bodies (Searle et al. 2009: 345). The South African Nursing Council was instrumental in moving nursing education into the realm of higher education and, as early as 1953 , nurse educators could follow diploma programmes at universities. The first degree programme to prepare professional nurses was introduced in 1955 at the University of Pretoria and, by 1969, several universities offered degree programmes for registration in general nursing. In the further development of degree programmes, disciplines such as midwifery, psychiatric nursing and community health nursing were included and offered as integrated programmes. Nursing Colleges entered into associative agreements with Universities in 1983 in an attempt to maintain quality through peer review processes (Searle et al. 2009: 347). The training of two sub-categories of nurses, namely the enrolled nurse and the enrolled nursing auxiliary mainly occurred at service level in hospitals, old age homes and others since the 1960s.

The introduction of the NQF provided an opportunity for revisiting all nursing qualifications and, following a resolution by SANC, except for the nursing auxiliary category, all nursing qualifications will move mainly to the higher education sector. See Table 2.2

- The proposed Nursing Qualifications in terms of the ten-level NQF is illustrated in table 2. NQF level 6 for a diploma in nursing requires that the staff nurse should have detailed knowledge of the theory and practice of nursing. At this level, the staff nurses should have problem-solving skills and demonstrate an understanding of ethical implications and decisions. They should also be able to apply well-developed processes of analysis, synthesis and evaluation of the 
information that is accessed. Furthermore, the staff nurse should demonstrate an understanding of the relationships between systems, evaluate performance against given criteria and work effectively in a team or group and take responsibility for own decisions and actions.

- $\quad$ The NQF level 7 for the Advanced Diploma (120) Midwife implies that after three years learning a Staff Nurse can register for an Advanced Diploma in Midwifery (120 credits). At this level, the learner should demonstrate the ability to integrate knowledge within the main areas of nursing theory and practice. The learner should also apply a range of methods to solve a problem, act ethically based on the appropriate ethical values of the profession and recognize that problemsolving is context and system bound. Furthermore, the learner should also show that $s /$ he can evaluate and address his or her own learning needs in a self-directed manner and facilitate a collaborative learning process. The NQF level 8 for the Bachelor's degree for a Professional Nurse and Midwife consists of 480 credits. The postgraduate diploma of 120 credits applies to specialization areas. The theories and practice of nursing should be understood in line with nursing theories, research methodologies and their application. The learner should interrogate multiple sources of knowledge in their area of specialization, should have the ability to communicate academic and professional ideas and offer creative insights, rigorous interpretations and solutions to problems. S/he should manage his or her own learning in a selfcritical manner and apply learning strategies that effectively address professional and ongoing learning needs.

- The NQF level 9 applies to the Master's degree and consists of 180 credits. Nurses who hold Master's degrees should be able to engage with and critique current research, as well as designing, selecting and applying appropriate and creative methods to complex practical and theoretical problems. With regard to problem- solving, the learner should use a wide range of specialized skills in identifying, conceptualizing, designing and implementing methods of enquiry to address complex and challenging problems of nursing practice. He or she needs to make autonomous ethical decisions and possess the ability to contribute critically to the development of ethical standards within the nursing profession. Nurses with master's degrees should be able to review current research in an area of specialization in nursing and communicate and defend substantial ideas that are the product of research or development in an area of specialization. Intervening at an appropriate level within the healthcare system and addressing the intended and unintended consequences of such interventions are also vital. Learners should develop their own learning strategies so as to sustain independent learning and academic and professional development and, furthermore, ensure good resource management and governance practices.

- NQF level 10 applies to the doctoral degree and comprises 360 credits. The learner should demonstrate expertise and critical knowledge in nursing theory and practice and have the ability to conceptualise new research initiatives and to create new knowledge or practice. An ability to develop new methods, techniques, processes and systems and to be original, creative and innovative is also a primary goal. The candidate should be able to apply critically reflexive, creative and novel ways to address complex practical and theoretical problems, as well as being able to manage data in an interactive process of analysis and synthesis for the development of significant original insights into new complex and abstract ideas, information or issues pertaining to nursing. Such a student has the ability to produce substantial independent, indepth and publishable work which meets international standards, and also to make a significant 
contribution to the discipline of nursing by developing a communication strategy to disseminate and defend research. Doctoral students should independently design, sustain and manage change within the healthcare system and demonstrate intellectual independence, research leadership and management of research and research development in nursing.

Table 2.2: The Nursing Qualifications in terms of the NQF

\begin{tabular}{|l|l|}
\hline NQF Level & Nursing Qualification \\
\hline 10 & $\bullet \quad$ Doctorate (360 credits) \\
\hline 9 & $\bullet \quad$ Master's degree (180 credits) \\
\hline 8 & $\begin{array}{l}\bullet \quad \text { Bachelor's degree (480 credits) } \\
\text { (Professional nurses and midwives) } \\
\text { (Nurses specializing in specific disciplines such as nursing management, nursing } \\
\text { education, theatre technique, and others) }\end{array}$ \\
\hline 7 & $\begin{array}{l}\bullet \quad \text { Advanced diploma (120 credits) } \\
\text { Midwife }\end{array}$ \\
\hline 6 & $\begin{array}{l}\bullet \quad \text { Diploma (360 credits) } \\
\text { (Staff Nurse) }\end{array}$ \\
\hline 5 & Higher certificate (120 credits) \\
\hline
\end{tabular}

\section{Conclusion}

The purpose of this chapter was to give a brief overview of the progression of nursing education over two decades, illustrating how nursing programmes evolved to meet the needs of the community, as well as complying with the quality standards and higher education criteria for acceptability and registration. The new qualifications framework has not yet been implemented and is being delayed by the many layers of approval required by the South African system. Many quite radical changes have been proposed, and it is important for the profession to evaluate both the implementation of these proposals and the effect they have within the system. To make this possible, a range of baseline studies should be done immediately in order to allow for evaluation of the changes.

\section{References}

Council on Higher Education (CHE). 2007. Review of Higher Education in South Africa: Selected Themes. Pretoria: CHE.

Department of Health. 2008. Nursing Strategies for South Africa. Pretoria: DoH

Fouche, N.A. 2007. What does the occupation-specific dispensation in the public service mean for nursing? http//findarticles.com. Accessed 06-10-2011.

Gwele, N.S. \& Uys, L.R. 1995. Views of leading nurse educators regarding the comprehensive basic nursing programme. Curationis 18 (1): 5-10. 
Isaacs, S.B.A. 2000. The National Qualifications Framework and the Standards Setting. Pretoria: SAQA.

Kotzé, W.J. 1995. The South African Nursing Council: 50 years of professional self-regulation. Curationis .18 (3): 16-26.

Mekwa, J. 2000. Chapter 13: Transformation in nursing education. In A Ntuli (Ed) South African Health Review 2000 (pp271-284). South Africa: Health Systems Trust.

Nkomo, M. 2000. The National Qualifications Framework and Curriculum Development. SAQA. www.saqa.co.za. Accessed 29-08-2011.

Pick, W.M., Nevhutalu, K., Cornwall, J.T. \& Masuku, M. 2001. Human Resources for Health: A National Strategy. Pretoria: Department of Health.

SANC. 2005. Draft Charter of Nursing Practice. Pretoria: SANC.

SANC. 2005. Nursing Act No. 33 of 2005. Pretoria: SANC.

Searle, C., Human, S. \& Mogotlane, S.M. 2009. Professional Practice: A Southern African Nursing Perspective. $5^{\text {th }}$ edition. Pretoria: Heinemann.

South Africa. 2004. Ministry of Education. The Higher Education Qualifications Framework. July 2004. Pretoria: Government Gazette No 0000000.

South Africa. 2009. National Qualifications Framework Act 67 of 2008. Government Gazette No. 31909: Pretoria.

www.hesa.org.za/stratgetic-plan; Accessed 30-08-2011.

www.saqa.org.za Accessed 29-08-2011.

www.sanc.co.za Accessed 2013-08-05 